\title{
The Effect of Switching from Tenofovir Disoproxil Fumarate (TDF) to Tenofovir Alafenamide (TAF) on Liver Enzymes, Glucose, and Lipid Profile
}

This article was published in the following Dove Press journal: Drug Design, Development and Therapy

\author{
Nicola Squillace, (D) 'Elena Ricci, (iD) ${ }^{2}$ \\ Barbara Menzaghi, (iD) ${ }^{3}$ \\ Giuseppe Vittorio De Socio, (iD ${ }^{4}$ \\ Simone Passerini, ${ }^{5}$ Canio Martinelli, ${ }^{6}$ \\ Maria Sabrina Mameli, ${ }^{7}$ \\ Paolo Maggi, (iD ${ }^{8}$ Katia Falasca, (D) ${ }^{9}$ \\ Laura Cordier, $^{5}$ \\ Benedetto Maurizio Celesia, (iD) ${ }^{10}$ \\ Elena Salomoni, (D) ${ }^{\prime \prime}$ \\ Antonio Di Biagio, (iD) ${ }^{12}$ \\ Giovanni Francesco Pellicanò, (ID) ${ }^{13}$ \\ Paolo Bonfanti (iD) \\ On behalf of the CISAI Study Group
}

'Infectious Diseases Unit ASST-MONZA, San Gerardo Hospital-University of Milano-Bicocca, Monza, Italy; '“"ASIA" Foundation ONLUS, Milan, Italy; 'Unit of Infectious Diseases, ASST della Valle Olona, Busto Arsizio, Italy; ${ }^{4}$ Department of Internal Medicine 2, Infectious Diseases Unit, "Santa Maria della Misericordia" General Hospital, Perugia, Italy; ${ }^{5}$ st Department of Infectious Diseases, ASST Fatebenefratelli Sacco, Milan, Italy; ${ }^{6}$ Infectious Diseases Unit, Careggi Hospital, Florence, Italy; 'Unit of Infectious Diseases, Department of Medical, Surgical and Experimental Sciences, University of Sassari, Sassari, Italy;

${ }^{8}$ University of Campania "Luigi Vanvitelli", Napoli, Italy; ${ }^{9}$ Clinic of Infectious Diseases, Department of Medicine and Science of Aging, University

"G. d'Annunzio" Chieti-Pescara, Chieti, Italy;

${ }^{10}$ Unit of Infectious Diseases, University of Catania, ARNAS Garibaldi, Catania, Italy; "Infectious Diseases Unit, Santa Maria Annunziata Hospital, Usl centro, Florence, Italy; ${ }^{12}$ Infectious Diseases, San Martino Hospital Genoa, Genoa, Italy;

${ }^{13}$ Department of Human Pathology of the Adult and the Developmental Age "G. Barresi", Unit of Infectious Diseases, University of Messina, Messina, Italy

Correspondence: Nicola Squillace Infectious Diseases Unit, Azienda Socio Sanitaria Territoriale di MONZA, San Gerardo Hospital-University of Milano-Bicocca, Via

Pergolesi 33, Monza 20900, Italy

Tel +390392339588

Fax +390392339327

Email nicolasquillace74@gmail.com
Objective: We aimed to investigate the effect of switching from tenofovir disoproxil fumarate (TDF) to tenofovir alafenamide (TAF) on the hepatic safety and metabolic profile. Methods: Consecutive HIV patients, enrolled in the Surveillance Cohort Long-term Toxicity Antiretrovirals/Antivirals (SCOLTA) project, switching from TDF to TAF were included. Changes from baseline (T0) to 6-month follow-up (T1) were evaluated using paired $t$-test and signed rank test.

Results: A total of 190 patients switched from TDF to TAF and had one 6-month follow-up visit. They were $80 \%$ male, $74.2 \%$ at CDC stage A-B, $93.7 \%$ with undetectable HIV-viral load. Mean age was $46.7 \pm 10.7$ years, body mass index was $25.0 \pm 3.9 \mathrm{~kg} / \mathrm{m}^{2}$, median CD4 cell count was 634 cell $/ \mu \mathrm{L}$ (interquartile range $[\mathrm{IQR}]=439-900$ ), aspartate aminotransferase (AST) was 23 $(\mathrm{IQR}=19-30) \mathrm{IU} / \mathrm{L}$, and alanine aminotransferase (ALT) was $24(\mathrm{IQR}=17-34) \mathrm{IU} / \mathrm{L}$. At T1, both AST (median=-1, IQR=-5-2 IU/L, $P=0.004$ ) and ALT (median=-2, IQR=-7-3 IU/L, $P=0.0004$ ) showed a significant decrease. Among 28 patients with ALT $>40$ at baseline, reduction was significant both clinically $(-17, \mathrm{IQR}=-32--1)$ and statistically $(P=0.0003)$. Total cholesterol levels (TC) increased $(+13.4 \pm 3.8 \mathrm{mg} / \mathrm{dL}, P=0.0006)$, as well as HDL-cholesterol (HDL-C) $(+3.8$ $\pm 1.2 \mathrm{mg} / \mathrm{dL}, P=0.02)$, LDL Cholesterol (LDL-C) $(+7.6 \pm 3.4, P=0.03)$ and glucose $(+4.0$ $\pm 1.8 \mathrm{mg} / \mathrm{dL}, P=0.02)$. D:A:D: and Framingham risk score did not change at 6 months after switch. Conclusion: A significant reduction of liver enzymes was observed after switching from TDF to TAF, especially in subjects with initial level of ALT >40 IU/L. Glucose, TC, HDL-C, and LDL-C increased, with no effect on cardiovascular risk scores.

Keywords: HIV, TDF, TAF, liver enzymes

\section{Introduction}

Switching from tenofovir disoproxil fumarate (TDF) to tenofovir alafenamide (TAF) showed a beneficial effect on bone and kidney toxicity. ${ }^{1,2}$ The impact on lipid profile is usually characterized by an increase in total cholesterol (TC) with a stable TC/high density lipoprotein cholesterol (HDL-C) ratio. ${ }^{3}$ Consistent findings emerged from different settings. ${ }^{4}$

Few data are available about potential hepatic toxicity of TDF. In 21,485 participants observed for 105,413 person-years, ${ }^{5}$ the D:A:D study reported an increased risk of chronic liver enzyme elevation, both with recent ( $<2$ years) and prolonged exposure to TDF ( $>2$ years), comparable to the risk related to didanosine and stavudine use. Data reported in a female pre-exposure prophylaxis (PREP) trial showed a higher risk of mild-to-moderate alanine transaminase (ALT) and aspartate 
transaminase (AST) elevation in subjects receiving TDF vs subjects in the placebo arm, especially if previously exposed to HBV virus or vaccination. ${ }^{6}$

Significant differences were also observed in patients with HBV infection: a normalization of liver enzymes was more frequently achieved in the TAF than in the TDF arm. ${ }^{7}$

In this analysis, our primary aim was to investigate the role of TAF on hepatic toxicity in a group of subjects, enrolled in the SCOLTA cohorts, who switched from emtricitabine (FTC)/TDF to FTC/TAF, maintaining the same third drug. The secondary objective was to evaluate the impact of the switch on lipid and glucose profile, and on estimated cardiovascular risk.

\section{Methods}

The SCOLTA Project (Surveillance Cohort Long-Term Toxicity of Antiretrovirals) is a prospective, observational, multicenter study created to assess the incidence of adverse events (AE) in patients receiving new antiretroviral drugs in clinical practice.

The SCOLTA Project is an on-line pharmacovigilance program currently involving 21 Italian infectious disease departments, where grade III and IV AEs (according to DAIDS table ${ }^{8}$ ) are recorded. All patients starting one of the cohort drugs are asked to participate in the study, after signing a written informed consent form.

\section{Ethics}

The study protocol was approved by the local ethics committee of the coordinating center at Hospital "L. Sacco" - University of Milan on September 18, 2002. A new protocol amendment was submitted and approved on June 13, 2013 by the same ethics committee. This last version was approved by the local ethics committee of each group and written consent was obtained from all participants. The study was conducted in accordance with the Declaration of Helsinki.

Data are available on reasonable request addressed to the corresponding author.

\section{Patients}

Patients undergo follow-up at 6-month intervals and AEs are notified when they are clinically observed. Complete data collection and follow-up procedures for the cohorts are described elsewhere. ${ }^{9}$

In this analysis, we included patients enrolled in three cohorts: darunavir (DRV)/cobicistat (COBI), elvitegravir $(\mathrm{EVG}) / \mathrm{COBI}$, and dolutegravir (DTG), who entered the study with TDF/FTC backbone and switched to TAF/FTC. After the switch, patients naïve at study entry were defined as on "second line antiretroviral therapy (ART)", to distinguish them from subjects who were ART-experienced at study entry. We selected subjects with AST and ALT both at switch (T0) and at 6-month follow-up (T1). We also calculated the 5-year risk for coronary heart disease (CHD), using the D:A:D equation ${ }^{10}$ and the Framingham risk score (FRS) equation, ${ }^{11}$ keeping age and smoking habits at $\mathrm{T} 0$ both in the $\mathrm{T} 0$ and $\mathrm{T} 1$ score.

\section{Statistical Analysis}

Categorical and discrete variables were described as frequency and percentage (\%). Continuous variables were described using mean and standard deviation (SD) if normally distributed, and median and interquartile range (IQR) if not normally distributed. At univariate analysis, groups were compared using chi-square for categorical variables and analysis of variance for continuous variables, or via non-parametric tests for non-normally distributed continuous variables. Repeated measures were analyzed as change from baseline and described as means ( \pm standard error, SE) if normally distributed or medians (IQR) if not normally distributed; to evaluate if change from baseline was significantly different from zero, we used the paired $t$-test or the signed rank test, as appropriate.

\section{Results}

One hundred and ninety patients (mean age $=44.8$ years, range $=19-74$ ) were selected for this analysis. Forty-two individuals who switched from TDF to TAF and had not yet reached T1 were excluded: no statistically significant difference was observed between these groups, in terms of sex, age, ART experience, third drug, BMI, and baseline AST and ALT, although women were more frequent in the group without follow-up visit at the time of this analysis (33.3\% vs $20.0 \%, P=0.06)$.

Among selected individuals, most were males $(80.0 \%)$ and $50(26.3 \%)$ were on their second-line ART. Median time from enrollment to switch was 23 months $(I Q R=14-31)$. The main characteristics are shown in Table 1. At baseline, we had complete data for calculating CHD risk for 70 (D:A:D:) and 77 (FRS) patients.

After 6 months of follow-up (Table 2), we observed a significant decrease both in AST (median $=-1, \mathrm{IQR}=-5-$ $2 \mathrm{IU} / \mathrm{L}, P=0.004)$ and in ALT $(-2, \mathrm{IQR}=-7-3 \mathrm{IU} / \mathrm{L}$, $P=0.0004)$ levels. Median ALT decrease was significant in patients with baseline values $>40 \mathrm{IU} / \mathrm{L}(P=0.0003): 15$ 
Table I Patients Switching from Tenofovir Disoproxil Fumarate (TDF) to Tenofovir Alafenamide (TAF), with 6-Month Follow-Up

\begin{tabular}{|c|c|}
\hline Variables & $N=190$ \\
\hline Age (years), mean $\pm S D$ & $46.7 \pm 10.7$ \\
\hline BMI $\left(\mathrm{kg} / \mathrm{m}^{2}\right)$, mean $\pm S D$ & $25.0 \pm 3.9$ \\
\hline Males, n (\%) & $152(80.0 \%)$ \\
\hline \multicolumn{2}{|l|}{ Characteristics of HIV infection } \\
\hline Risk factor IVDU, n (\%) & $35(18.4 \%)$ \\
\hline CDC Stage C, n (\%) & $51(26.8 \%)$ \\
\hline HCV coinfection, $n(\%)$ & $46(24.2 \%)$ \\
\hline Second-line ART, n (\%) & $50(26.3 \%)$ \\
\hline Undetectable HIV-RNA at switch, n (\%) & 178 (93.7\%) \\
\hline CD4+ (cells/mL), median (IQR) & $634(439-900)$ \\
\hline $\begin{array}{l}\text { ART duration (years) in multi-experienced patients, } \\
\text { median (IQR) }\end{array}$ & $9.9(4.8-17.8)$ \\
\hline \multicolumn{2}{|l|}{ Third drug, $\mathrm{n}(\%)$} \\
\hline Elvitegravir & $112(59.0 \%)$ \\
\hline Dolutegravir & $34(17.9 \%)$ \\
\hline Darunavir/Cobicistat & $44(23.1 \%)$ \\
\hline \multicolumn{2}{|l|}{ Laboratory values } \\
\hline Total cholesterol $(\mathrm{mg} / \mathrm{dL})$, mean $\pm \mathrm{SD}$ & $195 \pm 39$ \\
\hline $\mathrm{HDL}$ cholesterol $(\mathrm{mg} / \mathrm{dL})$, mean $\pm \mathrm{SD}$ & $48 \pm 16$ \\
\hline $\mathrm{LDL}$ cholesterol $(\mathrm{mg} / \mathrm{dL})$, mean $\pm \mathrm{SD}$ & $120 \pm 35$ \\
\hline Triglycerides (mg/dL), median (IQR) & $108(80-154)$ \\
\hline TC/HDL-C ratio, median (IQR) & $4.1(3.4-5.0)$ \\
\hline Blood glucose $(\mathrm{mg} / \mathrm{dL})$, mean $\pm \mathrm{SD}$ & $91 \pm 21$ \\
\hline AST (IU/L), median (IQR) & $23(19-30)$ \\
\hline ALT (IU/L), median (IQR) & $24(17-34)$ \\
\hline eGFR $(\mathrm{mL} / \mathrm{min})$, mean $\pm \mathrm{SD}$ & $86.1 \pm 19.2$ \\
\hline \multicolumn{2}{|l|}{ Coronary heart disease score $D: A: D: *(N=70)$} \\
\hline Low $(<1.0 \%)$ & $21(30.0 \%)$ \\
\hline Moderate $(1-<5 \%)$ & $33(47.1 \%)$ \\
\hline High $(5-<10 \%)$ & $12(17.1 \%)$ \\
\hline Very high ( $\geq 10 \%)$ & $4(5.7 \%)$ \\
\hline Median (IQR) & $1.75(0.68-4.83)$ \\
\hline \multicolumn{2}{|l|}{ Framingham risk score $(\%$ 10-year risk) $(\mathrm{N}=77)$} \\
\hline Low $(<5.0 \%)$ & $40(52.0 \%)$ \\
\hline Moderate $(5-<10 \%)$ & $15(19.5 \%)$ \\
\hline High $(10-<20 \%)$ & 14 (18.2\%) \\
\hline Very high ( $\geq 20 \%$ ) & $8(10.4 \%)$ \\
\hline Median (IQR) & $4.0(1.0-10.0)$ \\
\hline
\end{tabular}

Note: *Estimated \% of 5-year risk for coronary heart disease.

Abbreviations: IVDU, intravenous drug users; CDC, center for disease control; HCV, hepatitis C virus; eGFR, estimated glomerular filtration rate; SD, standard deviation; IQR, interquartile range; BMI, body mass index; ART, antiretroviral therapy, HDL, high density lipoprotein; LDL, low-density lipoprotein; AST, aspartate aminotransferase; ALT, alanine transaminase.

(53.6\%) had ALT $\leq 40$ at T1, six (21.4\%) did not normalize but experienced a decline, and seven (25.0\%) showed unchanged or increased values.

Statistically significant AST and ALT variations were found in patients negative both for $\mathrm{HCV}-\mathrm{Ab}$ and $\mathrm{HBs} \mathrm{Ag}$ $(-1, \quad \mathrm{IQR}=-5-2, \quad P=0.03 ; \quad-2, \quad \mathrm{IQR}=-7-2, \quad P=0.003$ respectively), whereas an ALT decrease was of borderline significance in individuals with positive $\mathrm{HCV}-\mathrm{Ab}$ and/or Hbs-Ag (Table 2). During the observation period, no patient with active $\mathrm{HCV}$ infection underwent treatment with direct-acting antivirals.

As regards metabolic variables and weight variation at T1 (Table 3), we observed that estimated glomerular filtration rate (eGFR) slightly increased $(+3.6 \pm 1.0 \mathrm{~mL} / \mathrm{min}$, $P=0.0008$ ), whereas BMI value or weight did not significantly change. TC increased $(+13.4 \pm 3.8 \mathrm{mg} / \mathrm{dL}$, $P=0.0006)$, as well as HDL-C $(+3.8 \pm 1.2 \mathrm{mg} / \mathrm{dL}, P=0.02)$ and LDL-C $(+7.6 \pm 3.4 \mathrm{mg} / \mathrm{dL}, P=0.03)$. As a result, mean $\mathrm{TC} / \mathrm{HDL}$ ratio showed a negligible variation.

Glucose significantly increased $(+4.0 \pm 1.8 \mathrm{mg} / \mathrm{dL}$, $P=0.02$ ), in particular in patients on EVG/COBI as the third drug $(+5 \pm 1.8 \mathrm{mg} / \mathrm{dL}, P=0.02)$.

As regards CHD risk, mean variations are reported in Table 3. According to D:A:D: score, five patients switched to a higher risk class (one low to intermediate risk, three from intermediate to high risk, one high to very high risk) and four switched to a lower risk class. According to Framingham risk score, four migrated to a higher risk class, vs eight to a lower risk class.

In the 6 months after switching to TAF, eight (4.2\%) patients interrupted the treatment: two for adverse events (one central nervous system symptoms, one TC increase); one patient died for aplastic anemia; two switched to a one-pill regimen; one had a therapeutic failure; one patient moved to another center; and one patients switched because the current regimen had interactions with treatment for benign prostatic hyperplasia.

\section{Discussion}

In this sample of patients switching from FTC/TDF to FTC/TAF we found a significant decrease of liver enzymes levels (both AST and ALT). Since the most marked decline was observed in patients with initial ALT level $>40 \mathrm{IU} / \mathrm{L}$, this variation may be clinically relevant.

TDF liver toxicity was demonstrated in animal models. It was reported as mild/moderate and consisted in collagen deposition and cytomegaly, apparently reversible after TDF withdrawal. ${ }^{12,13}$ Increased oxidative stress and lipid peroxidation were proposed as possible mechanisms to explain the observed liver abnormalities.

Studies on TDF/FTC used for PREP focused on bone and kidney toxicity and usually did not report liver adverse events. ${ }^{14}$ A study on pre-exposure prophylaxis (PREP) in African women demonstrated an increase in AST/ALT 
Table 2 Liver Transaminase Changes from TDF-TAF Switch to 6-Month Follow-UP

\begin{tabular}{|c|c|c|c|c|c|}
\hline & & \multicolumn{2}{|l|}{ AST (IU/L) } & \multicolumn{2}{|l|}{ ALT (IU/L) } \\
\hline & & Median, IQR & $P^{*}$ & Median, IQR & $P^{*}$ \\
\hline Overall & 190 & $-1(-5$ to 2$)$ & 0.004 & $-2(-7$ to 3$)$ & 0.0004 \\
\hline \multicolumn{6}{|l|}{ HCV-Ab } \\
\hline Neg & 144 & $-1(-4$ to 3$)$ & 0.08 & $-1(-7$ to 3$)$ & 0.01 \\
\hline Pos & 46 & $-2(-9$ to $I)$ & 0.009 & $-3(-11$ to 2$)$ & 0.0007 \\
\hline \multicolumn{6}{|l|}{ HBsAg } \\
\hline Neg & 173 & $-1(-5$ to 2$)$ & 0.003 & $-2(-8$ to 2$)$ & 0.0003 \\
\hline Pos & 17 & $0(-4$ to 4$)$ & 0.97 & I $(-6$ to 4$)$ & 0.86 \\
\hline \multicolumn{6}{|l|}{ HCV-Ab/HBsAg } \\
\hline Neg/neg & 133 & $-1(-5$ to 2$)$ & 0.03 & $-2(-7$ to 2$)$ & 0.003 \\
\hline $\mathrm{HCV}$ and/or $\mathrm{HBsAg}$ pos. & 57 & $-2(-7$ to 2$)$ & 0.08 & $-2(-7$ to 3$)$ & 0.05 \\
\hline \multicolumn{6}{|c|}{ HCV active infection at baseline } \\
\hline No & 178 & $-1(-5$ to 2$)$ & 0.004 & $-2(-7$ to 3$)$ & 0.005 \\
\hline Yes & 12 & $-4(-18$ to 10$)$ & 0.48 & $-1(-27$ to 6$)$ & 0.48 \\
\hline \multicolumn{6}{|l|}{ Baseline level AST } \\
\hline$\leq 40$ & 175 & -1 ( -4 to 2$)$ & 0.03 & - & - \\
\hline$>40$ & 15 & $-18(-23$ to -2$)$ & 0.07 & - & - \\
\hline \multicolumn{6}{|l|}{ Baseline level ALT } \\
\hline$\leq 40$ & 162 & - & - & $-I(-6$ to 4$)$ & 0.047 \\
\hline$>40$ & 28 & - & - & $-17(-32$ to -1$)$ & 0.0003 \\
\hline
\end{tabular}

Note: *Signed rank test.

Abbreviations: IQR, interquartile range; AST, aspartate aminotransferase; ALT, alanine aminotransferase; HCV-Ab, hepatitis C virus-antibodies; HBsAg, hepatitis B surface antigen.

levels in patients randomized to the TDF/FTC arm vs placebo, especially in patients with previous exposure to HBV. ${ }^{6}$ A beneficial effect in HBV infection could be explained by the higher concentration of TAF vs TDF in hepatocytes, demonstrated in animal models. ${ }^{15}$

Table 3 Changes in BMI and Metabolic Variables from TDF-TAF Switch to 6-Month Follow-Up

\begin{tabular}{|l|l|l|}
\hline & Variables & $\boldsymbol{P}$ \\
\hline Weight $(\mathrm{kg})$, mean \pm SE & $-0.3 \pm 0.4$ & 0.40 \\
BMI $\left(\mathrm{kg} / \mathrm{m}^{2}\right)$, mean $\pm \mathrm{SE}$ & $-0.1 \pm 0.1$ & 0.39 \\
Total cholesterol $(\mathrm{mg} / \mathrm{dL})$, mean $\pm \mathrm{SE}$ & $13.4 \pm 3.8$ & 0.0006 \\
HDL-cholesterol $(\mathrm{mg} / \mathrm{dL})$, mean $\pm \mathrm{SE}$ & $2.8 \pm 1.2$ & 0.02 \\
TC/HDL-C ratio, mean $\pm \mathrm{SE}$ & $0.01 \pm 0.09$ & 0.93 \\
LDL-cholesterol $(\mathrm{mg} / \mathrm{dL})$, mean $\pm \mathrm{SE}$ & $7.6 \pm 3.4$ & 0.03 \\
Triglycerides $(\mathrm{mg} / \mathrm{dL})$, median $(\mathrm{IQR})$ & $3(-21$ to 42$)$ & 0.09 \\
Blood glucose $(\mathrm{mg} / \mathrm{dL})$, mean $\pm \mathrm{SE}$ & $4.0 \pm 1.8$ & 0.02 \\
eGFR (mL/min), mean $\pm S E$ & $3.6 \pm 1.0$ & 0.0008 \\
Coronary heart disease score D:A:D, mean $\pm \mathrm{SE}$ & $0.05 \pm 0.09$ & 0.59 \\
Framingham risk score, mean $\pm \mathrm{SE}$ & $0.16 \pm 0.32$ & 0.62 \\
\hline
\end{tabular}

Abbreviations: SE, standard error; BMI, body mass index; HDL, high density lipoprotein; TC, total cholesterol; LDL, low-density lipoprotein; eGFR, estimated glomerular filtration rate.
Studies on switching from TDF to TAF showed that HBV-infected patients had a higher probability to normalize ALT level in the TAF than in the TDF arm. ${ }^{7}$

However, in our cohort HBV infection is not associated with a higher decrease of AST and ALT levels. This lack of evidence could be explained by the limited number of HBV positive patients in our cohort. Besides, liver transaminase variations were similar in HCV-Ab/HBs-Ag negative and $\mathrm{HCV}-\mathrm{AB}$ and/or $\mathrm{HBs}-\mathrm{Ag}$ positive patients, suggesting a potential mechanism not linked to viral coinfections. Liver toxicity is associated with mitochondrial dysfunction, ${ }^{16,17}$ and recent observations demonstrated a lower mitochondrial toxicity of TAF vs TDF. ${ }^{18,19}$ Thus, the better liver toxicity profile of TAF might be linked to a direct drug effect on liver, due to its lower mitochondrial toxicity. An alternative explanation could be the lower impact on progression of liver steatosis.

Glucose levels increased significantly in our cohort, in particular in patients on EVG. Although EVG was associated with alteration of adipokines and cytokines and glucose transporter GLUT4, ${ }^{20}$ no increase in insulin resistance was found in healthy male volunteers, exposed to 
a short-term treatment of 14 days with $\mathrm{EVG} / \mathrm{COBI} / \mathrm{FTC} /$ TAF. ${ }^{21}$ Nevertheless, our results could be justified by a longer exposure to EVG and TAF in our sample. The effect of EVG on glucose was not correlated with weight gain, because no significant difference in BMI was observed in patients on EVG vs patients on DTG or DRV. In the light of these results, EVG associated with TAF might have a direct effect on glucose metabolism.

Most patients in our sample were on an Integrase Strand Transfer Inhibitors (INSTI) containing regimen. INSTI class was recently associated with weight gain, especially in association with TAF, in naïve patients. ${ }^{22}$ We did not observe a significant change in BMI, probably because weight gain usually happens during the first year of INSTI treatment, ${ }^{23}$ and most patients in our sample switched to TAF after 12 months of INSTI-based treatment.

Consistent with findings from randomized controlled trials, ${ }^{1-3}$ we confirmed in a "real life setting" that eGFR showed a slight improvement. Moreover, we found that total cholesterol and LDL-C increased, with no significant change in TC/HDL ratio.

As regards cardiovascular risk, in a previous retrospective study, conducted on 273 patients introducing TDF, ${ }^{24}$ a significant modification of D:A:D score was observed after 3 months from switch. Similarly, in a randomized controlled trial, ${ }^{25} 311$ patients switched from $\mathrm{ABC}+3 \mathrm{TC}$ to TDF+FTC, with a significant reduction of Framingham risk both at 12 and 48 weeks. In our sample, changes in blood lipids did not determine a significant variation in cardiovascular risk scores after 6 months from switch.

\section{Conclusions}

Our findings suggest that switching from TDF to TAF has a beneficial effect on liver function. A significant increase of glucose, TC, HDL-C, and LDL-C did not result in significant change of cardiovascular risk estimations, as measured by D:A:D: and Framingham risk scores.

\section{Acknowledgments}

We thank all the members of Coordinamento Italiano Studio Allergie e Infezione da HIV (CISAI).

Coordinators: Paolo Bonfanti (Monza), Antonio Di Biagio (Genova).

Data Management: Elena Ricci (Monza).

Participating centers: G. Chichino, C Bolla, A. Parisini, E. Sarchi (Alessandria); A. Saracino, D. Bavaro, G. Angarano (Bari); L. Calza (Bologna); B. Menzaghi, M. Farinazzo (Busto Arsizio); G. Angioni (Cagliari); P. Maggi (Caserta); M. Gussio,
B. M. Celesia (Catania); K. Falasca (Chieti); A. Mastroianni, G. Guadagnino (Cosenza); F. Vichi, E. Salomoni (Firenze); C. Martinelli (Firenze); S. Ferrara (Foggia); A. Di Biagio, L. Taramasso, M. Berruti, M. Bassetti (Genova); C. Molteni, S. Piconi (Lecco); G. F. Pellicanò, G Nunnari (Messina); L. Valsecchi, L. Cordier, S. Parisini, G. Rizzardini (Milano); S. Rusconi, F. Conti (Milano); A. Bandera, A. Gori (Milano); D. Motta, M. Puoti (Milano); N. Squillace, P. Bonfanti (Monza); S. Martini (Napoli); O. Bargiacchi, P. L. Garavelli (Novara); A. Cascio, M. Trizzino (Palermo); R. Gulminetti (Pavia); G. V. De Socio, M. Nofri, D. Francisci (Perugia); D. Cibelli, G. Parruti (Pescara); C. Dentone, G. Cenderello (Sanremo); G. Madeddu, M. S. Mameli (Sassari); G. Orofino, M. Guastavigna (Torino).

The abstract of this paper was presented at "HIV Drug Therapy" October 28-31, 2018, Glasgow, Scotland, UK as an abstract presentation with preliminary findings. The poster's abstract was published in "Poster Abstracts" in the conference's website (http://hivglasgow.org/wpcontent/ uploads/2018/11/P218.pdf).

\section{Disclosure}

Nicola Squillace reports personal fees from ViiV Healthcare and grants from Gilead science, outside the submitted work. Benedetto Maurizio Celesia reports personal fees and non-financial support from MSD, Janssen cilag grants, personal fees, non-financial support, consultancy from Gilead sciences, grants, personal fees, nonfinancial support, consultancy from ViiV healthcare, outside the submitted work. Paolo Bonfanti reports personal fees from ViiV, Gilead, Jannsen, and Merck, outside the submitted work. The authors report no other potential conflicts of interest for this work.

\section{References}

1. Mills A, Crofoot G, McDonald C, et al. Tenofovir alafenamide versus tenofovir disoproxil fumarate in the first protease inhibitor-based single-tablet regimen for initial HIV-1 therapy: a randomized phase 2 study. J Acquir Immune Defic Syndr. 2015;69(4):439-445. doi:10. 1097/QAI.0000000000000618

2. Raffi F, Orkin C, Clarke A, et al. Brief report: long-term (96-week) efficacy and safety after switching from tenofovir disoproxil fumarate to tenofovir alafenamide in HIV-infected, virologically suppressed adults. J Acquir Immune Defic Syndr. 2017;75(2):226-231. doi:10. 1097/QAI.0000000000001344

3. Wohl D, Oka S, Clumeck N, et al. Brief report: a randomized, double-blind comparison of tenofovir alafenamide versus tenofovir disoproxil fumarate, each coformulated with elvitegravir, cobicistat, and emtricitabine for initial HIV-1 treatment: week 96 results. $J$ Acquir Immune Defic Syndr. 2016;72(1):58-64. doi:10.1097/QAI.00000 00000000940 
4. Kauppinen KJ, Kivela P, Sutinen J. Switching from tenofovir disoproxil fumarate to tenofovir alafenamide significantly worsens the lipid profile in a real-world setting. AIDS Patient Care STDS. 2019;33(12):500-506. doi:10.1089/apc.2019.0236

5. Kovari H, Sabin CA, Ledergerber B, et al. Antiretroviral drugs and risk of chronic alanine aminotransferase elevation in human immunodeficiency virus (HIV)-monoinfected persons: the data collection on adverse events of anti-HIV drugs study. Open Forum Infect Dis. 2016;3(1):ofw009.

6. Mandala J, Nanda K, Wang M, et al. Liver and renal safety of tenofovir disoproxil fumarate in combination with emtricitabine among African women in a pre-exposure prophylaxis trial. $B M C$ Pharmacol Toxicol. 2014;15:77. doi:10.1186/2050-6511-15-77

7. Agarwal K, Brunetto M, Seto WK, et al. 96weeks treatment of tenofovir alafenamide vs. tenofovir disoproxil fumarate for hepatitis B virus infection. J Hepatol. 2018;68(4):672-681. doi:10.1016/j. jhep.2017.11.039

8. Division of AIDS. Division of AIDS (DAIDS) Table for Grading the Severity of Adult and Pediatric Adverse Events. Bethesda, MD: National Institute of Allergy and Infectious Diseases; 2017. Available from: https://rsc.niaid.nih.gov/sites/default/files/daidsgra dingcorrectedv21.pdf. Accessed December 9, 2020.http://rcc.techres-intl.com/tox_tables.htm

9. Bonfanti P, Martinelli C, Ricci E, et al. An Italian approach to postmarketing monitoring: preliminary results from the SCOLTA (Surveillance Cohort Long-Term Toxicity Antiretrovirals) project on the safety of lopinavir/ritonavir. J Acquir Immune Defic Syndr. 2005;39(3):317-320. doi:10.1097/01.qai.0000164248.56722.3c

10. Friis-Moller N, Thiebaut R, Reiss P, et al. Predicting the risk of cardiovascular disease in HIV-infected patients: the data collection on adverse effects of anti-HIV drugs study. Eur J Cardiovasc Prev Rehabil. 2010;17(5):491-501. doi:10.1097/HJR.0b013e328336a150

11. D'Agostino RB, Grundy S, Sullivan LM, Wilson P; Group CHDRP. Validation of the Framingham coronary heart disease prediction scores: results of a multiple ethnic groups investigation. JAMA. 2001;286(2):180-187. doi:10.1001/jama.286.2.180

12. Adaramoye OA, Adewumi OM, Adesanoye OA, Faokunla OO, Farombi EO. Effect of tenofovir, an antiretroviral drug, on hepatic and renal functional indices of Wistar rats: protective role of vitamin E. J Basic Clin Physiol Pharmacol. 2012;23(2):69-75. doi:10.1515/ jbcpp.2011.0042

13. Peter AI, Naidu EC, Akang E, et al. Investigating organ toxicity profile of tenofovir and tenofovir nanoparticle on the liver and kidney: experimental animal study. Toxicol Res. 2018;34(3):221-229. doi:10.5487/TR.2018.34.3.221

14. Fonner VA, Dalglish SL, Kennedy CE, et al. Effectiveness and safety of oral HIV preexposure prophylaxis for all populations. AIDS. 2016;30(12):1973-1983. doi:10.1097/QAD.0000000000001145
15. Murakami E, Wang T, Park Y, et al. Implications of efficient hepatic delivery by tenofovir alafenamide (GS-7340) for hepatitis B virus therapy. Antimicrob Agents Chemother. 2015;59(6):3563-3569. doi:10.1128/AAC.00128-15

16. Lee J, Park JS, Roh YS. Molecular insights into the role of mitochondria in non-alcoholic fatty liver disease. Arch Pharm Res. 2019;42(11):935-946.

17. Hua $\mathrm{H}$, Zhang $\mathrm{Z}$, Qian $\mathrm{Y}$, et al. Inhibition of the mitochondrial complex-1 protects against carbon tetrachloride-induced acute liver injury. Biomed Pharmacother. 2019;115:108948. doi:10.1016/j. biopha.2019.108948

18. Ritou EKT. In vitro modelling of the impact of TAF on cellular bioenergetics in immune cells and hepatocytes. 21st International workshop on co-morbidities and adverse drug reactions in HIV; 5-6 November 2019, 2019; Basel, Switzerland. Antivir Ther. 2019;24(S1):A100.

19. Li M, Zhou L, Dorsey HG, et al. Tenofovir alafenamide does not inhibit mitochondrial function and cholesterol biosynthesis in human T lymphoblastoid cell line. Antiviral Res. 2020;183:104948. doi:10.1016/j.antiviral.2020.104948

20. Moure R, Domingo P, Gallego-Escuredo JM, et al. Impact of elvitegravir on human adipocytes: alterations in differentiation, gene expression and release of adipokines and cytokines. Antiviral Res. 2016;132:59-65. doi:10.1016/j.antiviral.2016.05.013

21. Spinner CD, Schulz S, Bauer U, et al. Effects of antiretroviral combination therapies $\mathrm{F} / \mathrm{TAF}, \mathrm{E} / \mathrm{C} / \mathrm{F} / \mathrm{TAF}$ and $\mathrm{R} / \mathrm{F} / \mathrm{TAF}$ on insulin resistance in healthy volunteers: the TAF-IR study. Antivir Ther. 2018;23(7):629-632. doi:10.3851/IMP3271

22. Sax PE, Erlandson KM, Lake JE, et al. Weight gain following initiation of antiretroviral therapy: risk factors in randomized comparative clinical trials. Clin Infect Dis. 2020;71:1379-1389.

23. Taramasso L, Bonfanti P, Ricci E, et al. Factors associated with weight gain in people treated with dolutegravir. Open Forum Infect Dis. 2020;7(6):ofaa195. doi:10.1093/ofid/ofaa195

24. Gagliardini R, Fabbiani M, Colafigli M, et al. Lipid-lowering effect and changes in estimated cardiovascular risk after switching to a tenofovir-containing regimen for the treatment of HIV-infected patients. J Chemother. 2017;29(5):299-307. doi:10.1080/1120009X. 2016.1269040

25. Campo R, DeJesus E, Bredeek UF, et al. SWIFT: prospective 48-week study to evaluate efficacy and safety of switching to emtricitabine/tenofovir from lamivudine/abacavir in virologically suppressed HIV-1 infected patients on a boosted protease inhibitor containing antiretroviral regimen. Clin Infect Dis. 2013;56 (11):1637-1645. doi:10.1093/cid/cis 1203

\section{Publish your work in this journal}

Drug Design, Development and Therapy is an international, peerreviewed open-access journal that spans the spectrum of drug design and development through to clinical applications. Clinical outcomes, patient safety, and programs for the development and effective, safe, and sustained use of medicines are a feature of the journal, which has also been accepted for indexing on PubMed Central. The manuscript management system is completely online and includes a very quick and fair peer-review system, which is all easy to use. Visit http://www. dovepress.com/testimonials.php to read real quotes from published authors. 